\title{
Introduction to eco-efficient pavement materials
}

\author{
F. Pacheco-Torgal ${ }^{1}$ and Serji Amirkhanian ${ }^{2}$ \\ ${ }^{1} \mathrm{C}$-TAC Research Centre, University of Minho, Guimarães, Portugal, ${ }^{2}$ University of \\ Alabama, Tuscaloosa, AL, United States
}

\subsection{The state of the Planet}

Almost 50 years ago several scientists used a system dynamics computer model to simulate the interactions of population, food production, industrial production, pollution, and consumption of nonrenewable natural resources, having predicted that during the 21 st century the Earth's capacity would be exhausted, resulting in the collapse of human civilization [1]. Two decades later, in an update of this study, the same authors showed that some limits had already been crossed [2]. Meadows et al. [3] conducted a 30-year update of the original study and concluded that period was nothing than a waste of time and that Humanity has done very little to avoid the collapse of the Planet's environment. Turner [4] also studied Meadows' projections with 30 years of real events and concluded that the global system is on an unsustainable trajectory unless there is a substantial and rapid reduction in consumptive behavior. One year later Rockström et al. [5] suggested an innovative approach for global sustainability defining nine interdependent planetary boundaries. They also stated that humanity has already transgressed three planetary boundaries for changes to the global nitrogen cycle, rate of biodiversity loss, and above all climate change. More details on the suggested planetary boundaries framework can be found in Ref. [6]. The UN Intergovernmental Panel on Climate Change released a special report warning that "Limiting global warming to $1.5^{\circ} \mathrm{C}$ would require rapid, far-reaching, and unprecedented changes in all aspects of society" [7]. The target of $1.5^{\circ} \mathrm{C}$ is being the threshold beyond which climate change would imperil species survival. Randers et al. [8] stated that the world will not reach all Sustainable Development Goals by 2030, nor by 2050, and that the global safety margin will continue to decline. And in truth, Distelkamp and Meyer [9] mentioned that although the global average $\mathrm{CO}_{2}$ intensity is projected to decline against 2015, it is expected that global $\mathrm{CO}_{2}$ emissions will further increase by $44 \%$ up to $53 \mathrm{Gt}$ in 2050 . In order to keep economy running, several institutions such as UNEP, World Bank or the European Commission thus claim for green economy and green growth that is expected to do more with less while improving human wellbeing and social equity but some believe that that is not compatible with the ecologic limits of the Planet [10]. Some authors [11] stated that using a low-tech approach can not only contribute to an increase in resilience but can also create the 
cultural conditions needed for politics and macroeconomics of degrowth to emerge. On the other hand, Holford [12] reminded us not only that technology has control over humans but also that it is driven by the neoliberal socioeconomic quest for profit maximization and economic growth. And others even claim that only a severe shut down of the main carbon polluters could have meaningful results still they seem to forget that such action would have a major impact on the increase of poverty. One of the solutions recommended by several authors including the 2018 Nobel Laureate of Economy is the carbon tax. Nordhaus [13] suggested carbon tax as an important way for households, firms, and governments to reduce emissions cost-effectively. He also claimed that carbon prices will strengthen incentives for research and development of technologies that will lower the cost of reducing emissions. Others, however, claim that the wellbeing of the rich must decline rapidly as the only solution to ensure that the environmental burden associated with the rise of the wellbeing of the poor does not override the sustainable carrying capacity of planet Earth [14]. Be there as it may and while no wonder solutions are found, which can green industries without shutting it down, incremental improvements are the only short-term solution for the problem. This was the rationale that led to the concept of eco-efficiency first coined in the book "Changing course" [15] in the context of the 1992 Earth Summit process. This concept includes "the development of products ... while progressively reducing their environmental impact and consumption of raw materials throughout their life cycle, to a level compatible with the capacity of the planet."

\subsection{Scientific production on civil engineering and pavements}

Civil engineering is the scientific area that investigates and forms professions to deal with the challenges posed by the built environment that is still associated with the world's highest consumption of raw materials, as well as very high energy consumption. Of course the fact that recent surveys show that students interested in civil engineering do not believe in anthropogenic climate change $[16,17]$ is a problem that also requires urgent attention because it is impossible to enforce the ASCE Code of Ethics that states, "Engineers shall hold paramount the safety, health, and welfare of the public and shall strive to comply with the principles of sustainable development" with those that are skeptical on such principles. A shortcoming that is especially serious because climate change raises many questions with ethical dimensions rooted in the human condition $[18,19]$. In this context, perhaps the suggestion of [20] for civil engineers to play a role in helping developing countries can help overcome some of that skepticism. Concerning the subfield of pavements although being one of the major civil infrastructures represents a small subset in the larger field of civil engineering. It is worth noting that according to [21], the total mileage of roads has reached 70 million kilometers. Still, other authors [22] are more modest mentioning that asphalt roads span a distance of more than three times 
around the sun (around 13 million kilometers). But that value can hardly be an accurate one because the United States alone has 6.5 million kilometers of roads [23]. This author also mentioned that asphalt pavements cover an area, in the order of magnitude, of Cuba or Iceland $\left(100,000 \mathrm{~km}^{2}\right)$. A search on the Scopus database for all publications concerned with civil engineering shows that in the beginning of the 80 s, when publications about roads and pavements start to appear, other subfields of civil engineering already represented more than 700 publications per year (Fig. 1.1). Only in 1988 the number of pavement-related publications crossed 100 per year, still representing $0.8 \%$ of the civil engineering output. And only by 2004 research investigations in the field of roads and pavements were able to reach an accumulated number of more than 1000 publications that push that area to $1.6 \%$ of the civil engineering universe.

Currently, the accumulated number of Scopus publications concerned with civil engineering exceeds half a million and the subfield of roads and pavements still represents less than $2 \%$. Fig. 1.2 shows that in the subfield of publications concerning roads and pavements, the first publications concerned with sustainability appeared only in 2003. And only 7 years later the accumulated number of those publications reached 100. In 2018 the accumulated number of publications concerned with environmental aspects of roads and pavements has not yet reached $8 \%$ of the publications of that area. As shown in Fig. 1.3, the sustainability-related publications of all areas of civil engineering started to appear only by 1985 but around 2010 they were able to surpass all pavements and roads-related publications and since then these have increased in an exponential mode. Meaning that many of the advances carried out in the field of civil engineering were directly for certain

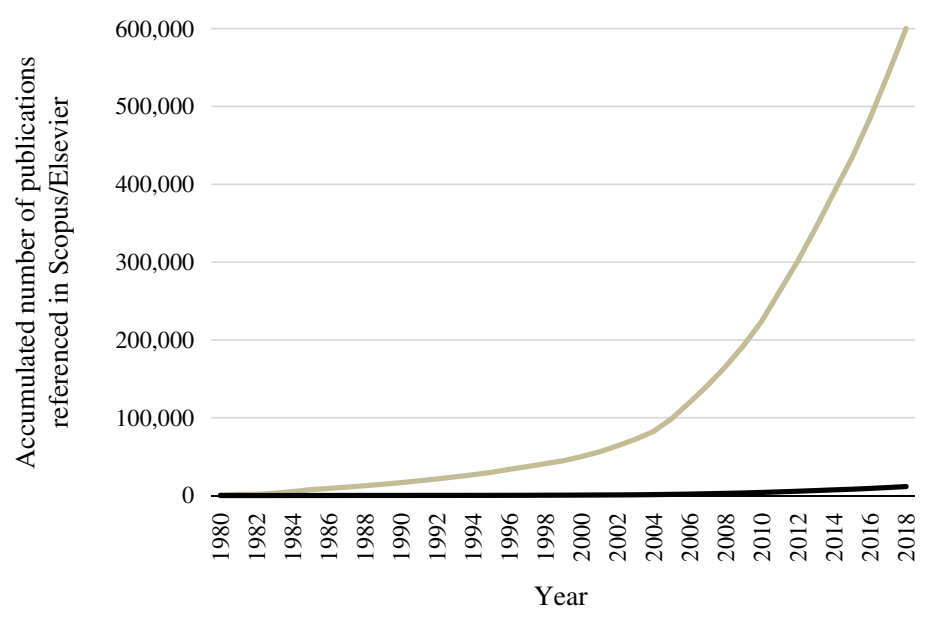

Figure 1.1 Evolution of the accumulated total number of publications (articles/reviews/ chapters, books, and referenced conference papers) in Scopus affiliated with Civil Engineering Departments (gray line) and the keywords "Roads" or "Pavements" searched in the section title (black line). 


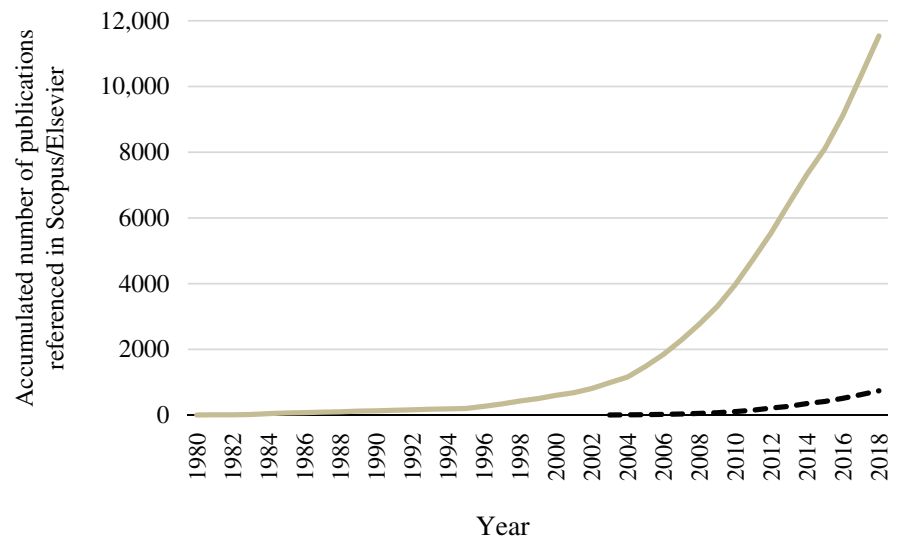

Figure 1.2 Evolution of the accumulated total number of publications (articles/reviews/ chapters, books, and referenced conference papers) in Scopus affiliated with Civil Engineering Departments having the keywords "Roads" or "Pavements" in the title (gray line) and the keywords "Sustainability," "Sustainable," "Eco-efficiency," and "Eco-efficient" searched in the section title, abstract and keywords (black dashed line).

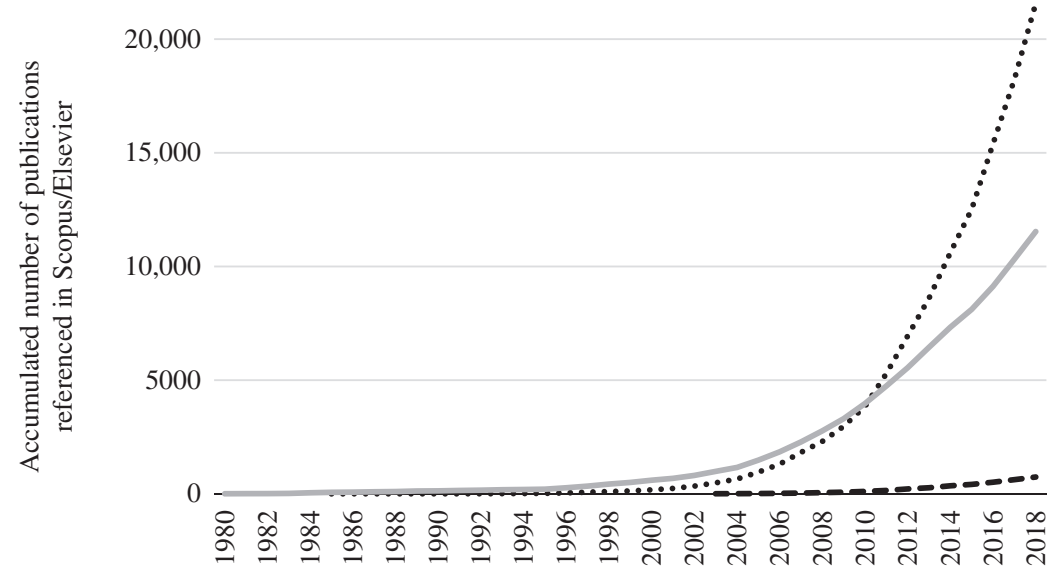

Figure 1.3 Evolution of the accumulated total number of publications (articles/reviews/ chapters, books, and referenced conference papers) in Scopus affiliated with Civil Engineering Departments having the keywords "Sustainability," "Sustainable," "Ecoefficiency," and "Eco-efficient" searched in the section title, abstract, and keywords (dotted line); the keywords "Roads" or "Pavements" in the title (gray line); and the keywords "Sustainability," "Sustainable," "Eco-efficiency," and "Eco-efficient" searched in the section title, abstract, and keywords (black dashed line).

subfields alone [24-27]. Only in 1988 has the number of pavement related publication cross one hundred per year still representing $0.8 \%$ of the civil engineering output. And only by 2004 were the researcher's investigation in the field of roads and pavements able to reach an accumulated number of more than 1000 publications 
that push that area to $1.6 \%$ of the Civil Engineering universe. This fact by itself constitutes a strong justification for this book. Concerning the sustainability of pavements, several issues merit an especial concern.

A first and obvious one is related to the Circular Economy where the value of products, materials, and resources is maintained in the economy for as long as possible, and the generation of waste minimized [28,29]. And that is why several chapters in the first part of this book are concerned with waste recycling and also life-cycle assessment (LCA). The other part concerns the influence of climate change on the durability of pavements. This is because some studies reported that thermal cracking in the asphalt pavement will decrease over the next 50 years, while rutting will occur earlier than expected [30]. And this has a direct influence on traffic accidents. Tsubota et al. [31] studied age and pavement types and their ages on the accident risk on urban expressway routes. The results showed that the age of road pavement has a positive effect on the accident risk and that the effect becomes remarkable under the rain condition on curve and tight-curve sections. That is why is worrying that in a rich country such as United States, the share of roads in poor condition nationwide increased from $14 \%$ to $20 \%$ between 2009 and 2017 [32]. It is also predicted that climate change will be associated with increased temperatures. Data show in MCCarthy [32] that the summers of 2016 and 2017 had some of the highest average surface temperatures ever recorded. It is worth mentioning that in India the intensity of heat wave for cities uses increases from $40^{\circ} \mathrm{C}$ in reference time frame to $45^{\circ} \mathrm{C}$ in short-term projection to $49^{\circ} \mathrm{C}$ in far future [33]. And that helps to explain why some roads have had cases of melting bitumen [34]. The temperature increase will be further aggravated due to urban heat island (UHI) (higher temperature of metropolitan areas than that of their surrounding countryside). UHI is triggered by absorption radiation due to artificial urban materials, transpiration from buildings and infrastructure, release of anthropogenic heat from inhabitants and appliances, and airflow blocking effect of buildings [35,36]. Concerning the Urban Heat Island Intensity (the difference in temperature between an urban site and a rural site), some projections show that in the northwest of the United Kingdom, summer mean temperatures could increase by $5^{\circ} \mathrm{C}\left(50 \%\right.$ probability, $7^{\circ} \mathrm{C}$ top of the range) by the 2080s [37]. Strangely Plati [38] cited [39] on the fact that permeable pavements could help to mitigate UHI effects. However, the work of those authors has nothing on the influence of permeable pavements on UHI. In fact pervious pavements help to reduce peak stormwater runoff, thereby preventing incidents of combined sewer overflows. It is important to remember that in 2017, more than 1000 people died and 45 million people lost homes, livelihoods, and services when severe floods hit Southeast Asian cities, including Dhaka in Bangladesh and Mumbai in India [40]. Pervious pavements are therefore an important feature for city resilience [41,42] and constitute another eco-efficient approach for pavement materials. Also very important is pavements with self-healing capacity that will allow for higher durability, reduced pavement maintenance, reduced resource consumption, reduced carbon emissions, and also reduced traffic congestion problems. In the United States alone, costs related to wasted fuel and time loss due to traffic congestion were estimated between 50 and 100 billion dollars [43,44]. That 
importance explains why is issue is addressed by four chapters in this book. And also why on June 13, 2019, it was considered one of the 100 Radical Innovation Breakthroughs (RIBs) for the future by a report of the European Commission [45]. Jiang et al. [21] recently presented a review on the performance, applications, and challenges of six environmentally friendly functional pavement materials, namely the permeable asphalt concrete, noise-reducing pavement materials, low heat-absorbing pavement materials, exhaust gas-decomposing pavement materials, deicing pavement materials, and energy harvesting pavement materials. For energy harvesting, they have included piezoelectric pavements, photovoltaic powergenerating pavements and also thermoelectricity pavements. Wang et al. [46] reviewed energy harvesting technologies and also included two mores technologies, solar collectors and geothermal (heat pipes with geothermal water). However, the cutting edge case of self-charging roads in which roads deliver energy to electric vehicles also needs to be highlighted as an important multifunctional asset of ecoefficient pavements; this case will be addressed in the last part of this book that also deals with the important issue of energy harvesting. It is worth mentioning that energy harvesting is one of the few RIBs with an impact on more than 15 global value networks [45]. All this means that in the 21st century, much will be expected from pavement materials as high added value multifunctional materials, not only to have enough durability being capable of high performance despite an increase in temperature stress, to help to tackle stormwater events, to help to reduce UHI effects but also to be able to generate energy and deliver it to electric vehicles.

\subsection{Outline of the book}

This book provides an updated state-of-the-art review on eco-efficient pavement materials. Part 1 of the book concerns pavements with recycled waste (Chapters 2-6).

Chapter 2, Utilization of scrap plastics in asphalt binders, addresses a case study on the use of three different postindustrial polyethylenes as partial replacement of bitumen in asphalt-based pavements.

Chapter 3, Use of waste engine oil in materials containing asphaltic components, discusses the use of waste engine oil in pavement materials containing asphaltic components. The refinement of waste engine oil, its properties, and its use in bituminous binders are covered.

Chapter 4, Microstructure and performance characteristics of cold recycled asphalt mixtures, reviews the microstructure performance of cold recycled asphalt mixtures.

Chapter 5, Life-cycle assessment of asphalt pavement recycling, reviews the LCA studies focusing on asphalt pavement recycling, including hot, warm, and cold recycling methods, as well as in-plant and in-place recycling technologies.

Part 2 deals with pavements for climate change mitigation (Chapters 6-8). 
Chapter 6, Cool pavements, presents the UHI and the urban heating phenomena and provides an overview of cool pavement technologies, detailing areas that require further scientific investigation.

Chapter 7, Reflective coatings for high albedo pavement, reviews the LCA studies focusing on asphalt pavement recycling, including hot, warm, and cold recycling methods, as well as in-plant and in-place recycling technologies. The aim is to provide constructive recommendations and pointing out the potential research gaps for future studies.

Chapter 8, Influence of aging on the performance of cool coatings, summarizes the key parameters contributing to the aging of cool coatings, along with the main methods for assessing their weathering and aging; in the second part, the effect of the aging on the thermal performance of cool coatings, with regard to both the urban microclimate and the buildings' energy performance, is discussed.

Part 3 (Chapters 9-12) deals with self-healing pavements.

Chapter 9, Self-healing property and road performance of asphalt binder and asphalt mixture containing urea formaldehyde microcapsule, discusses the selfhealing ability and rheological property of asphalt binder containing urea formaldehyde resin self-healing microcapsule and other microcapsules.

Chapter 10, Self-healing biomimetic microvascular containing oily rejuvenator for prolonging life of bitumen, focuses on the case of hollow fibers containing oily rejuvenator fabricated by a one-step wet-spinning method using polyvinylidene fluoride resin.

Chapter 11, Self-healing pavements using microcapsules containing rejuvenator: from idea to real application, is concerned with the fabrication method of microcapsules containing oily rejuvenators, including controlling the mean size, shell thickness, mechanical property, and thermal stability.

Chapter 12, Novel magnetically induced healing in road pavements, addresses novel approaches to generate engineered healing capabilities through induction heating of ferrous material-asphalt composites. These include ferromagnetic fillers, ferrous fibers, mixed-metal alloy fibers, and recycled fibers from shredded vehicle tires, among others.

Finally, Part 4 concerns pavements with energy harvesting potential and vehicle power charging ability (Chapter 13-15).

Chapter 13, Thermoelectric technologies for harvesting energy from pavements, introduces the thermoelectric technologies for harvesting energy from pavements. It starts by presenting the basic principle of thermoelectric effect known as "Seebeck effect." It then explains the temperature characteristics of road surface, ambient air, and subgrade. Based on this, pavement-ambient thermoelectric system and pavement-subgrade thermoelectric system are introduced. At the end of the chapter, the problems and development of pavement thermoelectric technologies are analyzed and discussed.

Chapter 14, Piezoelectric energy harvesting from pavement, reviews piezoelectric energy harvesting from pavement. It includes piezoelectric materials, principle of energy harvesting, and piezoelectric transducer designs and types. It reviews previous studies on piezoelectric energy harvesting in pavement, as well as the use and 
storage of harvested energy and challenges of piezoelectric energy harvesting in pavement.

Chapter 15, Inductive power transfer technology for road transport electrification, closes Part 4 reviewing electrified road system feasibility studies conducted with the aim of bridging these emergent gaps, which serve as an opening-up work in this new research area.

\section{References}

[1] D.L. Meadows, D.H. Meadows, J.R.W. Behrene, The Limits to Growth, MIT Press, 1972.

[2] D.L. Meadows, D.H. Meadows, J. Randers, Beyond the Limits: Global Collapse or Sustainable Future, Earthscan, 1992.

[3] D.H. Meadows, J. Randers, D.L. Meadows, The Limits to Growth: The 30-Year Update, Routledge, 2004.

[4] G.M. Turner, A comparison of the limits to growth with 30 years of reality, Glob. Environ. Chang. 18 (3) (2008) 397-411.

[5] J. Rockström, W. Steffen, K. Noone, Å. Persson, F.S. Chapin III, E. Lambin, et al., Planetary boundaries: exploring the safe operating space for humanity, Ecol. Soc. 14 (2) (2009) 32.

[6] J. Rockström, K. Richardson, Planetary boundaries: separating fact from fiction. A response to Montoya et al, Mar. Pollut. Bull. 92 (2018) 170-179.

[7] IPCC, Special report on global warming of $1.5^{\circ} \mathrm{C}$ (SR15). < http://www.ipcc.ch/report/ $\operatorname{sr} 15 />, 2018$

[8] J. Randers, J. Rockstrøm, P.E. Stoknes, U. Goluke, D. Collste, S. Cornell, Achieving the 17 sustainable development goals within 9 planetary boundaries, EarthArXiv. Oct. (2018) 2.

[9] M. Distelkamp, M. Meyer, Pathways to a resource-efficient and low-carbon Europe, Ecol. Econ. 155 (2019) 88-104.

[10] P.E. Stoknes, J. Rockström, Redefining green growth within planetary boundaries, Energy Res. Soc. Sci. 44 (2018) 41-49.

[11] S. Alexander, P. Yacoumis, Degrowth, energy descent, and 'low-tech' living: potential pathways for increased resilience in times of crisis, J. Clean. Prod. 197 (2016) $1840-1848$.

[12] W.D. Holford, The future of human creative knowledge work within the digital economy, Futures 105 (2018) 143-154.

[13] W.D. Nordhaus, Revisiting the social cost of carbon, Proc. Natl. Acad. Sci. U. S. A. 114 (7) (2017) 1518-1523.

[14] M. Büchs, M. Koch, Challenges for the degrowth transition: the debate about wellbeing, Futures 105 (2019) 155-165.

[15] Stephan Schmidheiny with BCSD, Changing Course: A Global Perspective on Development and the Environment, MIT Press, Cambridge, MA, 1992.

[16] T. Shealy, R. Valdes-Vasquez, L. Klotz, G. Potvin, A. Godwin, J. Cribbs, et al., Half of students interested in civil engineering do not believe in anthropogenic climate change, J. Prof. Issues Eng. Educ. Pract. 143 (3) (2016) D4016003. 
[17] E. Grubert, Civil engineering's internal skepticism on climate change, J. Prof. Issues Eng. Educ. Pract. 144 (3) (2018) 02518003.

[18] A. Kaklauskas, F. Pacheco-Torgal, S. Grafakos, V. Lapinskiene, Built environment life cycle process and climate change, Nearly Zero Energy Building Refurbishment: A Multidisciplinary Approach, Springer Verlag, London, UK, 2013, pp. 61-97.

[19] A. Willis, Constructing a story to live by: ethics, emotions and academic practice in the context of climate change, Emot. Space Soc. 5 (2012) 52-59.

[20] R.J. Houghtalen, J.A. Abdalla, J. Caldwell, J.K. Aidoo, R.C. Ward, J.H. Hanson, Civil engineering volunteerism: assisting developing countries stem the tide of economic migration, J. Prof. Issues Eng. Educ. Pract. 143 (4) (2017) 02517003.

[21] W. Jiang, Y. Huang, A. Sha, A review of eco-friendly functional road materials, Constr. Build. Mater. 191 (2018) 1082-1092.

[22] M. Parti, Towards improved testing of modern asphalt pavements. Mater. Struct. 51 (2018) 166.

[23] FS, Materials in Use in U.S. Interstate Highways. Fact Sheet < https://pubs.usgs.gov/fs/ 2006/3127/2006-3127.pdf>, 2006.

[24] B. Roure, C. Anand, V. Bisaillon, B. Amor, Systematic curriculum integration of sustainable development using life cycle approaches: the case of the Civil Engineering Department at the Université de Sherbrooke, Int. J. Sustain. High. Educ. 19 (3) (2018) 589-607.

[25] L.A. Sierra, V. Yepes, E. Pellicer, A review of multi-criteria assessment of the social sustainability of infrastructures, J. Clean. Prod. 187 (2018) 496-513.

[26] E.K. Zavadskas, J. Antucheviciene, T. Vilutiene, H. Adeli, Sustainable decision-making in civil engineering, construction and building technology, Sustainability 10 (1) (2017) 14.

[27] E. Zavadskas, J. Šaparauskas, J. Antucheviciene, Sustainability in Construction Engineering, MDPI, 2018.

[28] S. Huysman, J. De Schaepmeester, K. Ragaert, J. Dewulf, S. De Meester, Performance indicators for a circular economy: a case study on post-industrial plastic waste, Resources, Conserv. Recycling 120 (2017) 46-54.

[29] EC (European Commission), Closing the Loop - An EU Action Plan for the Circular Economy, Brussels, 2015.

[30] A. Jamshidi, K. Kurumisawa, G. White, T. Nishizawa, T. Igarashi, T. Nawa, et al., State-of-the-art of interlocking concrete block pavement technology in Japan as a postmodern pavement, Constr. Build. Mater. 200 (2019) 713-755.

[31] T. Tsubota, C. Fernando, T. Yoshii, H. Shirayanagi, Effect of road pavement types and ages on traffic accident risks, Transport. Res. Procedia 34 (2018) 211-218.

[32] N. MCCarthy, The US states with the worst roads. <https://www.statista.com/chart/ 18047/share-of-major-public-roads-classified-as-being-in-poor-condition/>, 2019.

[33] R. Sharma, H. Hooyberghs, D. Lauwaet, K. De Ridder, Urban heat island and future climate change_implications for Delhi's heat, J. Urban Health 96 (2) (2019) 235-251.

[34] Hartley, A., Melting bitumen leaves motorists 'sinking' into Queensland road, destroys tyres. <https://www.abc.net.au/news/2018-07-05/melting-road-in-far-north-queensland/ $9942800>, 2018$.

[35] P.A. Mirzaei, F. Haghighat, Approaches to study urban heat island - abilities and limitations, Build. Environ. 45 (10) (2010) 2192-2201.

[36] F. Pacheco-Torgal, J. Labrincha, L. Cabeza, C.G. Granqvist (Eds.), Eco-efficient Materials for Mitigating Building Cooling Needs: Design, Properties and Applications, Woodhead Publishing, 2015 (No. 56). 
[37] G. Levermore, J. Parkinson, K. Lee, P. Laycock, S. Lindley, The increasing trend of the urban heat island intensity, Urban Clim. 24 (2018) 360-368.

[38] C. Plati, Sustainability factors in pavement materials, design, and preservation strategies: a literature review, Constr. Build. Mater. 211 (2019) 539-555.

[39] J. Yang, Z.-H. Wang, K.E. Kaloush, Environmental impacts of reflective materials: is high albedo a 'silver bullet' for mitigating urban heat island? Renew. Sustain. Energy Rev. 47 (2015) 830-843.

[40] X. Bai, R.J. Dawson, D. Ürge-Vorsatz, G.C. Delgado, A.S. Barau, S. Dhakal, et al., Six Research Priorities for Cities and Climate Change, 2018.

[41] F. Pacheco-Torgal, Eco-efficient construction and building materials research under the EU Framework Programme Horizon 2020, Constr. Build. Mater. 51 (2014) 151-162.

[42] T. Elmqvist, E. Andersson, N. Frantzeskaki, T. McPhearson, P. Olsson, O. Gaffney, et al., Sustainability and resilience for transformation in the urban century, Nat. Sustain. 2 (4) (2019) 267.

[43] Hooper, A., Cost of Congestion to the Trucking Industry: 2018 Update, 2018.

[44] E. Schlangen, S. Sangadji, Addressing infrastructure durability and sustainability by self-healing mechanisms - recent advances in self-healing concrete and asphalt, Procedia Eng. 54 (2013) 39-57.

[45] EU, 100 Radical Innovation Breakthroughs for the future. 13 June 2019, Brussels $<$ https://ec.europa.eu/info/sites/info/files/research_and_innovation/knowledge_publications_tools_and_data/documents/ec_rtd_radical-innovation-breakthrough_052019.pdf > , 2019.

[46] H. Wang, A. Jasim, X. Chen, Energy harvesting technologies in roadway and bridge for different applications - a comprehensive review, Appl. Energy 212 (2018) 1083-1094. 